\title{
COVID-19, chronic inflammatory rheumatic disease and anti-rheumatic treatments
}

\section{Dieu-Donné Ouédraogo ${ }^{1}$ (I) $\cdot$ Wendlassida Joelle Stéphanie Tiendrébéogo ${ }^{1} \cdot$ Fulgence Kaboré $^{1} \cdot$ Honoré Ntsiba $^{2}$}

Received: 15 April 2020 / Revised: 13 May 2020 / Accepted: 19 May 2020 / Published online: 29 May 2020

(C) International League of Associations for Rheumatology (ILAR) 2020

\begin{abstract}
Since December 2019, the pandemic caused by coronavirus disease 2019 (COVID-19) raises a real public health problem. COVID-19 appeared in Wuhan (Hubei province) in China. Drugs that have been used in rheumatology for decades seem to be effective in this infection and are for the most part being studied. The rational use of these anti-rheumatic drugs is based on the cytokinic storm (hyperproduction of IL1, IL6, TNF $\alpha$ ) in the body by COVID-19 in its severe form. In this review, the authors make the difference between the infectious and auto-inflammatory part of COVID-19; the disease does not seem to be a risk factor for admission to the intensive care unit for patients suffering from inflammatory rheumatism; however, the poverty of studies on this subject should be noted. The authors also review anti-rheumatic drugs while studying COVID-19 treatment.
\end{abstract}

Keywords Coronavirus $\cdot$ COVID-19 $\cdot$ Rheumatoid arthritis $\cdot$ Treatment

\section{Introduction}

Since December 2019, the pandemic caused by coronavirus disease 2019 (COVID-19) raises a real public health problem [1]. COVID-19 appeared in Wuhan (Hubei province) in China. COVID-19 (SARS-CoV 2) is a coronavirus with nearly $80 \%$ common nucleotide with SARS-CoV 1 [2]. It is manifested by fever, dry cough, rhinitis, asthenia, headache, and dyspnea but often by acute respiratory distress syndrome that can lead to death [3-5]. The mortality risk factors appear to be mainly diabetes, high blood pressure, coronary heart disease, chronic obstructive lung disease, and chronic kidney disease [6].

Although hypotheses are made, the pathogenesis of COVID-19 is not clearly elucidated. Choices of treatment are therefore empirical based on previous experience with SARS-CoV1 or Milddle East Respiratory Syndrome (MERS-CoV) [7-9]. Antiretrovirals (Lopinavir/Ritonavir, Remdesivir, Ribavirin) have been tried in treating patients [10-13]. In addition, drugs that have been used in

Dieu-Donné Ouédraogo ouedd@yahoo.fr

1 Department of Rheumatology, University Hospital of Bogodogo, BP: 628, Ouagadougou 09, Burkina Faso

2 Department of Rheumatology, University Hospital of Brazzaville, Brazzaville, Congo rheumatology for decades seem to be effective in this infection and are for the most part being studied $[8,14-16]$. The rational of use of these anti-rheumatic drugs is based on the cytokinic storm (hyperproduction of IL1, IL6, TNF $\alpha$ ) in the body by COVID-19 in its severe form [7, 14, 17, 18]. Rheumatologists with their experience in administration of these drugs could help improve their use [16].

COVID-19 therefore raises two major concerns for rheumatologists: do chronic inflammatory rheumatic diseases and their immunosuppressive treatment cause a risk of admission to intensive care units or high mortality in infected patient? Which anti-rheumatic drugs can be used to treat COVID-19?

\section{COVID-19}

\section{An infectious part}

Coronaviruses (CoVs) are viruses of the subfamily of Orthocoronavirinae from the family Coronaviridae. The name coronavirus, from Latin meaning "virus with a crown," is due to the appearance of virions under an electron microscope, with a fringe of large bulbous projections that resemble the solar corona [19].

Coronaviruses have a viral envelope with a positive RNA genome and a kilobase capsid (shell), which is incredibly large for an RNA virus. They are classified as Nidovirals, since all 
viruses of this order produce a nested set of sub-genomic mRNA during infection. Peak, envelope, membrane, and capsid proteins contribute to the overall structure of all coronaviruses. These RNA viruses are single-stranded (single-stranded) and positive (Baltimore Classification Group IV). They can mutate and recombine.

\section{An auto-inflammatory part}

Cytokine dysregulation is a particular interest in patients with COVID-19 infection [14, 17, 18, 20]. The host immune response is by one side essential for the resolution of COVID-19 infection, but it can also be crucial for the pathogenesis of major clinical manifestations of the disease. The angiotensin-converting enzyme 2 (ACE2) has been identified as the host cell-surface receptor for SARS-CoV2 envelope spike glycoprotein [21]. ACE2 is a type I membrane protein expressed on cells in the kidney, heart, gastrointestinal tract, blood vessels, and, importantly, lung AT2 alveolar epithelial cells, which are particularly prone to viral infection [22]. SARS-CoV-2 infection leads to the downregulation of ACE2 expression, thus resulting in excessive production of angiotensin II by the related enzyme ACE. It has been suggested that the stimulation of type 1a angiotensin II receptor (AGTR1A) increases pulmonary vascular permeability, thus potentially explaining the increased lung damage when the expression of ACE2 is decreased [23].

Sarzi-Puttini et al. hypothesized that the decrease in INFy in COVID-19 may suppress Th1 and favor Th2 [7]. Some of the cytokines seem to be up-regulated especially in patients with more severe disease and $\mathrm{T}$ cell depletion. Huang et al. found that IL-2, IL-7, IL-10, G-CSF, IP-10, MCP-1, MIP-1A, and TNF- $\alpha$ levels correlated with disease severity [24]. Diao et al. found that disease severity correlated with TNF- $\alpha$, IL-6, and IL-10 levels [25], thus documenting TNF- $\alpha$ hyperproduction in the serum of COVID-19 patients.

The regulation of this cytokine storm remains the challenge in the treatment of COVI-19 infection and explains the use of chloroquine and its derivatives, anti-cytokines (anti-IL1, antiIL6, anti-TNF), and anti-Jak.

\section{Is there an increased risk of COVID-19 infection in patients with chronic inflammatory rheumatic disease?}

The corona virus disease 2019 or COVID-19 pandemic is responsible for high mortality in patients with risk factors such as age over 70 years, diabetes, cardiovascular history, chronic respiratory disease, chronic renal failure on dialysis, cancers during treatment, immune deficiency, cirrhosis, obesity, and pregnant women [6]. Inflammatory rheumatism does not appear to be associated with admission to intensive care. Is a patient with chronic inflammatory rheumatism receiving immunosuppressive treatments not at risk for a severe form of VIDOC-19 infection? To date, little data are available on chronic inflammatory rheumatic diseases and COVID-19 [26].

Rheumatoid arthritis (RA) is associated with an increased risk of infection compared to a general population without RA [27]. This increased risk of infection is correlated with the presence of risk factors that are identical to those reported in COVID-19 [27, 28]. On the other hand, corticosteroids and non-steroidal anti-inflammatory drugs, by inhibiting the inflammatory response, increase the risk of infections, especially bacterial and mycotic infections [28, 29]. Methotrexate treatment does not appear to be associated with an increased risk of infection other than a combination with corticosteroids [30]. In contrast to methotrexate, the biological diseasemodifying anti-rheumatic drugs are responsible for an increased risk of infection correlated with advanced age, female sex, treatment with Prednisone at a dose over $7.5 \mathrm{mg} /$ day, and a high number of hospital stays [28].

The particularity of the pandemic of COVID-19 requires specific data for this infection. Monti S et al. studied the clinical course of COVID-19 in a series of patients with chronic arthritis treated with immunosuppressive targeted therapies [31]. The authors have collected information on 320 patients (female $68 \%$, mean age $55 \pm 14$ years) treated with bDMARDs or tsDMARDs (57\% with rheumatoid arthritis, $43 \%$ with spondyloarthritis, $52 \%$ treated with tumor necrosis factor inhibitors, $40 \%$ with other bDMARDs and $8 \%$ with tsDMARDs). Thirteen confirmed and/or suspected COVID19 patients were diagnosed. Only one patient required hospitalization and was 65 years of age. No deaths were observed [31]. Despite the small sample size in this study and the limited data on COVID-19 and inflammatory rheumatism, it seems to be a lower risk of severity and death in this group of patients apart from the usual risk factors (diabetes mellitus, hypertension, obesity...). In this study, it is also reported that in a reference center for the management of patients with COVID-19, out of 700 patients, no severe patient was under biological disease-modifying anti-rheumatic drugs [31]. Until further studies clarify the absence of higher risk in patients with chronic inflammatory rheumatism, increased monitoring of these patients is necessary and application of barrier gestures is useful for all.

\section{Anti-rheumatic treatments as a potential treatment for COVID-19}

\section{Chloroquine}

Chloroquine (or chloroquinine) is an antimalarial drug of the 4-aminoquinoline family that has been widely marketed in the 
form of salts (sulphate or phosphate). It is a medicine used for so long in preventive and curative treatment of malaria. For several decades, chloroquine has been used in rheumatology for its immunomodulating effect, particularly on systemic lupus erythematosus and rheumatoid arthritis. Studies have also shown the antiviral activity of chloroquine in vitro on $\mathrm{H} 5 \mathrm{~N} 1$ avian influenza [32], Chikungunya [33], Zika [34], Ebola [35], and SARS-Coronavirus 1 [36]. Chloroquine acts by increasing the endosomal $\mathrm{pH}$ required for viral/host cell fusion and, as demonstrated in studies on SARS-Cov, it may also interfere with the glycosylation of ACE2 receptors, which may inhibit viral entry into the target cell [36]. A systematic review of the efficacy and safety of chloroquine in the treatment of COVID-19 involving six articles and 23 ongoing clinical trials in China concluded that chloroquine is effective in limiting the replication of SARS-CoV-2 in vitro [37].

Basing on the action of chloroquine on COVID-19 through its in vitro efficacy and on the first results of open studies carried out in Beijing hospitals in Hunan province in central and southern China, in Guangdong province, Prof. Raoult's team proposes that it be used in the treatment of COVID-19 [15]. However, the therapeutic efficacy and safety of chloroquine are still being discussed [38, 39]. For Franck Touret and Xavier de Lamballerie of Inserm 1207 in Marseille, caution must be exercised in view of the previous antiviral failures of chloroquine in vivo and its deleterious effect during acute viral infections [38]. However, chloroquine appears to be effective in COVID-related acute respiratory distress syndrome, improves pulmonary radiological lesions, accelerates the seronegativity of the virus, and shortens the duration of the disease [39]. Chinese experts recommend that patients diagnosed as mild, moderate, and severe cases of COVID-19 pneumonia and without contraindications to chloroquine be treated with $500 \mathrm{mg}$ chloroquine twice a day for 10 days [40].

Since then, chloroquine has been incorporated into treatment protocols for COVID-19 infection in Asia [40] and many other countries.

\section{Hydroxychloroquine}

Hydroxychloroquine is a derivative of chloroquine; it differs from chloroquine by having a hydroxyl $(\mathrm{OH})$ group at the end of each chain. It has replaced chloroquine for many years in the treatment of systemic lupus erythematosus and rheumatoid arthritis.

The pharmacological activity of chloroquine and hydroxychloroquine was tested using SARS-CoV-2-infected Vero cells. Physiologically based pharmacokinetic models (PBPK) were implemented for both drugs separately by integrating their in vitro data. Using the PBPK models, hydroxychloroquine concentrations in lung fluid were simulated under 5 different dosing regimens to explore the most effective regimen while considering the drug's safety profile.
Hydroxychloroquine $(\mathrm{EC} 50=0.72 \mu \mathrm{M})$ was found to be more potent than chloroquine $(\mathrm{EC} 50=5.47 \mu \mathrm{M})$ in vitro. Based on PBPK models results, a loading dose of $400 \mathrm{mg}$ twice daily of hydroxychloroquine sulfate given orally, followed by a maintenance dose of $200 \mathrm{mg}$ given twice daily for 4 days, is recommended for SARS-CoV-2 infection, as it reached three times the potency of chloroquine phosphate when given $500 \mathrm{mg}$ twice daily 5 days in advance. Hydroxychloroquine was found to be more potent than chloroquine to inhibit SARS-CoV-2 in vitro [41].

This study is confirmed by other authors who suggest that in addition to its anti-viral and immunomodulatory effect, hydroxychloroquine had an anti-inflammatory effect that may mitigate the cytokine storm observed during COVID19 infection [42].

Zhou et al. propose that hydroxychloroquine (HCQ), which exhibits an antiviral effect highly similar to that of CQ, could serve as a better therapeutic approach. HCQ is likely to attenuate the severe progression of COVID-19, inhibiting the cytokine storm by suppressing $\mathrm{T}$ cell activation. They herein strongly urge that clinical trials are performed to assess the preventive effects of HCQ in both disease infection and progression [43]. In the same vein, Gautret $P$ et al. of Professor Raoult's team in an open label non-randomized study of 36 patients infected with COVID-19 showed a significant reduction in viral load at Day 6 of inclusion compared to controls and a lower mean duration of viral carriage than in untreated patients in the literature. Azithromycin added to hydroxychloroquine was significantly more efficient for virus elimination; all patients in Gautret el al study were proposed oral hydroxychloroquine sulfate $200 \mathrm{mg}$, three times per days during 10 days [44]. Among hydroxychloroquine-treated patients six received azithromycin (500 mg day 1 followed by $250 \mathrm{mg}$ per day, the next 4 days).

In our experience of hydroxychloroquine use in treating systemic lupus erythematosus and some forms of rheumatoid arthritis, 93 patients were included. The average cumulative dose of hydroxychloroquine was $376 \mathrm{~g}+405.48$ with extremes of $7 \mathrm{~g}$ and $2336 \mathrm{~g}$. The average duration of treatment with hydroxychloroquine was 2.83 years +2.89 years with extremes of 0.08 years and 15 years. Maculopathy was extremely rare $(2.1 \%)$ [45].

\section{Corticosteroid}

Using corticosteroids during COVID-19 infection is highly controversial. Chen et al. reported 19 (19\%) patients treated with corticosteroids for 3-15 days and methylprednisolone (1-2 $\mathrm{mg} / \mathrm{kg}$ per day) and recommend for patients with acute respiratory distress syndrome that this treatment be of the shortest possible duration [3]. For Zhang et al., adverse effects largely dominate the benefit of corticosteroids [14]. Wang et al. reported $62(44.9 \%)$ patients who received corticosteroid 
therapy without improvement [46]. Russel et al. reported clinical evidence did not support corticosteroid treatment for COVID-19 lung injury [47]. These studies are supported by others that report no benefit from corticosteroid therapy during COVD-19 infection [48, 49]. For Ling et al. the duration of viral RNA detection from oropharyngeal swabs and fecal samples in the glucocorticoid treatment group was longer than that in the non-glucocorticoid treatment group (15 days vs. 8.0 days, respectively; $t=2.550, P=0.013$ ) and the duration of viral RNA detection in fecal samples in the glucocorticoid treatment group was longer than that in the non-glucocorticoid treatment group (20 days vs. 11 days, respectively; $t=4.631$, $P<0.001)$. So these authors did not recommended glucocorticoids for treating COVID-19, especially for mild disease [36]. For Zheng et al. in severe COVID-19 patients, early and short-term use of low dose of methylprednisolone was beneficial and did not delay SARS-CoV-2 RNA clearance and influence $\operatorname{IgG}$ antibody production [50].

Due to the lack of evidences, the interium guideline of WHO does not support routinely give systemic corticosteroids for treatment of viral pneumonia outside of clinical trials [41]. A new randomized controlled trial (RCT) recently registered by Zhou et al. that will compare methylprednisolone via intravenous injection at a dose of $1-2 \mathrm{mg} / \mathrm{kg} /$ day for 3 days versus a control group not using glucocorticoid (ClinicalTrials.gov, ChiCTR2000029386) will help to answer some of our questions in the near future.

\section{Tocilizumab}

Tocilizumab (TCZ) is a recombinant human IL-6 monoclonal antibody, which specifically binds to soluble and membranebound IL-6 receptors (IL-6R), thus blocking IL-6 signaling and its mediated inflammatory response.

Totally, 15 patients with COVID-19 were included in Luo et al. study [51]. Two of them were moderately ill, 6 were seriously ill, and 7 were critically ill. The TCZ was used in combination with methylprednisolone (MP) in 8 patients. Five patients received the TCZ administration twice or more. Although TCZ treatment ameliorated the increased CRP in all patients rapidly, for the 4 critically ill patients who received only single dose of TCZ, 3 of them still dead and the CRP level in the rest 1 patient failed to return to normal range with a clinical outcome of disease aggravation. Serum IL-6 level tended to further spiked firstly and then decreased after TCZ therapy in 10 patients. A persistent and dramatic increase of IL- 6 was observed in these 4 patients who failed treatment.

Till now, several clinical trials have been registered on safety and efficacy of tocilizumab in the treatment of severe COVID-19 pneumonia in adult inpatients, including a multicenter, randomized controlled trial for the efficacy and safety of tocilizumab in the treatment of novel coronary pneumonia (NCP) (ChiCTR2000029765), a single arm open multicenter study on tocilizumab (ChiCTR2000030796), and combination of tocilizumab and other drugs (ChiCTR2000030442 and ChiCTR2000030894).

\section{Anti-Jak}

One of the known regulators of endocytosis is the AP2associated protein kinase 1 (AAK1). AAK1 inhibitors can interrupt the passage of the virus into cells and can be helpful in preventing virus infections. JAK inhibitor as well as an AAK1 inhibitor, was suggested a possible candidate for treatment of COVID-19, considering its relative safety and high affinity. Recently $\mathrm{Wu}$ et al. reviewed TH17 responses in patients with SARS-CoV-2 and proposed an FDA approved JAK2 inhibitor Fedratinib for reducing mortality of patients with TH17 type immune profiles [20]. Another author proposed Baricitinib as candidat to treat COVID-19 [14].

To date, there are some registered clinical trials of JAK inhibitor: "Study for safety and efficacy of Jakotinib hydrochloride tablets in the treatment of severe and acute exacerbation patients of novel coronavirus pneumonia (COVID-19)" (ChiCTR2000030170); "Severe novel coronavirus pneumonia (COVID-19) patients treated with ruxolitinib in combination with mesenchymal stem cells: a prospective, single blind, randomized controlled clinical trial" (ChiCTR2000029580).

\section{Colchicine}

Colchicine has been used safely in a variety of cardiovascular clinical conditions. Among its potential mechanisms of action is the non-selective inhibition of NLRP3 inflammasome, which is thought to be a major pathophysiologic component in the clinical course of patients with COVID-19. GRECCO19 trial aims to identify whether colchicine may positively intervene in the clinical course of COVID-19 [52]. It will be prospective, cluster randomized, open-labeled, controlled study. Patients with laboratory confirmed SARS-CoV-2 infection (under RT PCR) and clinical picture that involves temperature $>37.5{ }^{\circ} \mathrm{C}$ and at least two out of the (i) sustained coughing, (ii) sustained throat pain, (iii) Anosmia and/or ageusia, (iv) fatigue/tiredness, (v) $\mathrm{PaO} 2<95 \mathrm{mmHg}$ will be included. (The study has been submitted to clinicaltrials.gov on March 26, 2020.)

\section{Anti-TNF}

The hypothesis of anti-TNF use during COVID-19 infection is based on the pathophysiology of the disease [53]. Study evaluating adalimumab in COVID-19 infection has recently been registered in the Chinese Clinical Trial Registry (ChiCTR2000030089). 


\section{Conclusion}

Chronic inflammatory rheumatism does not seem to be a risk factor for the severity of COVID-19 despite the presence of immunosuppressive therapy. However, the studies are few and do not allow definitive conclusions to be drawn on the subject. Hydroxychloroquine and biological disease-modifying antirheumatic drugs (anti-IL6, anti-TNF, anti-IL1) are serious candidates for the treatment of COVID-19. If their efficacy were to be confirmed by the ongoing RCT studies, the next challenge for rheumatologists, infectious diseases specialists, and intensive care physicians would be to determine a window of opportunity, considered to be the best intervention in the best timeframe to increase a better progression of the disease.

\section{Compliance with ethical standards}

\section{Disclosures None.}

\section{References}

1. Organisation Mondiale de la Santé (OMS): www.euro.who.int/fr/ health-topics/health-emergencies/coronavirus-covid-19/news/ news/2020/3/who-announces-covid-19-outbreak-a-pandemic. Accessed 13 May 2020

2. Lu R, Zhao X, Li J et al (2020) Genomic characterisation and epidemiology of 2019 novel coronavirus: implications for virus origins and receptor binding. Lancet 395(10224):565-574. https:// doi.org/10.1016/S0140-6736(20)30251-8

3. Chen N, Zhou M, Dong X et al (2020) Epidemiological and clinical characteristics of 99 cases of 2019 novel coronavirus pneumonia in Wuhan, China: a descriptive study. Lancet 395(10223):507-513. https://doi.org/10.1016/S0140-6736(20)30211-7

4. Rodriguez-Morales AJ, Cardona-Ospina JA, Gutiérrez-Ocampo E et al (2020) Latin American Network of Coronavirus Disease 2019COVID-19 Research (LANCOVID-19). Electronic address: https:// www.lancovid.org. Clinical, laboratory and imaging features of COVID-19: a systematic review and meta-analysis. Travel Med Infect Dis:101623. https://doi.org/10.1016/j.tmaid.2020.101623

5. Lai CC, Liu YH, Wang CY, Wang YH, Hsueh SC, Yen MY, Ko WC, Hsueh PR (2020) Asymptomatic carrier state, acute respiratory disease, and pneumonia due to severe acute respiratory syndrome coronavirus 2 (SARS-CoV-2): facts and myths. J Microbiol Immunol Infect. https://doi.org/10.1016/j.jmii.2020.02.012

6. Zhou F, Yu T, Du R et al (2020) Clinical course and risk factors for mortality of adult inpatients with COVID-19 in Wuhan, China: a retrospective cohort study. Lancet 395(10229):1054-1062. https:// doi.org/10.1016/S0140-6736(20)30566-3

7. Sarzi-Puttini P, Giorgi V, Sirotti S et al (2020) COVID-19, cytokines and immunosuppression: what can we learn from severe acute respiratory syndrome? Clin Exp Rheumatol 38(2):337-342

8. Pires da Rosa G, Ferreira E (2020) Therapies used in rheumatology with relevance to coronavirus disease 2019. Clin Exp Rheumatol 38(2):370

9. Yao TT, Qian JD, Zhu WY, Wang Y, Wang GQ (2020) A systematic review of lopinavir therapy for SARS coronavirus and MERS coronavirus - a possible reference for coronavirus disease- 19 treatment option. J Med Virol 92:556-563. https://doi.org/10.1002/jmv.25729
10. Khalili JS, Zhu H, Mak A, Yan Y, Zhu Y (2020) Novel coronavirus treatment with ribavirin: groundwork for evaluation concerning COVID-19. J Med Virol. https://doi.org/10.1002/jmv.25798

11. Wu J, Li W, Shi X, Chen Z, Jiang B, Liu J, Wang D, Liu C, Meng Y, Cui L, Yu J, Cao H, Li L (2020) Early antiviral treatment contributes to alleviate the severity and improve the prognosis of patients with novel coronavirus disease (COVID-19). J Intern Med. https://doi.org/10.1111/joim. 13063

12. Bhatnagar T, Murhekar MV, Soneja M, Gupta N, Giri S, Wig N, Gangakhedkar R (2020) Lopinavir/ritonavir combination therapy amongst symptomatic coronavirus disease 2019 patients in India: protocol for restricted public health emergency use. Indian J Med Res. https://doi.org/10.4103/ijmr.IJMR_502_20

13. Cao B, Wang Y, Wen D, Liu W, Wang J, Fan G, Ruan L, Song B, Cai Y, Wei M, Li X, Xia J, Chen N, Xiang J, Yu T, Bai T, Xie X, Zhang L, Li C, Yuan Y, Chen H, Li H, Huang H, Tu S, Gong F, Liu Y, Wei Y, Dong C, Zhou F, Gu X, Xu J, Liu Z, Zhang Y, Li H, Shang L, Wang K, Li K, Zhou X, Dong X, Qu Z, Lu S, Hu X, Ruan S, Luo S, Wu J, Peng L, Cheng F, Pan L, Zou J, Jia C, Wang J, Liu X, Wang S, Wu X, Ge Q, He J, Zhan H, Qiu F, Guo L, Huang C, Jaki T, Hayden FG, Horby PW, Zhang D, Wang C (2020) A trial of lopinavir-ritonavir in adults hospitalized with severe Covid-19. N Engl J Med 382:1787-1799. https://doi.org/10.1056/ NEJMoa2001282

14. Zhang W, Zhao Y, Zhang F, Wang Q, Li T, Liu Z, Wang J, Qin Y, Zhang X, Yan X, Zeng X, Zhang S (2020) The use of antiinflammatory drugs in the treatment of people with severe coronavirus disease 2019 (COVID-19): the experience of clinical immunologists from China. Clin Immunol 214:108393. https://doi.org/ 10.1016/j.clim.2020.108393

15. Ferro F, Elefante E, Baldini C, Bartoloni E, Puxeddu I, Talarico R, Mosca M, Bombardieri S (2020) COVID-19: the new challenge for rheumatologists. Clin Exp Rheumatol 38(2):175-180

16. Cron RQ, Chatham WW (2020) The rheumatologist's role in Covid-19. J Rheumatol. https://doi.org/10.3899/jrheum.200334

17. Qin C, Zhou L, Hu Z et al (2020) Dysregulation of immune response in patients with COVID-19 in Wuhan, China. Clin Infect Dis. https://doi.org/10.1093/cid/ciaa248

18. Li G, Fan Y, Lai Y, Han T, Li Z, Zhou P, Pan P, Wang W, Hu D, Liu X, Zhang Q, Wu J (2020) Coronavirus infections and immune responses. J Med Virol 92(4):424-432. https://doi.org/10.1002/ jmv. 25685

19. Guo YR, Cao QD, Hong ZS, Tan YY, Chen SD, Jin HJ, Tan KS, Wang DY, Yan Y (2020) The origin, transmission and clinical therapies on coronavirus disease 2019 (COVID-19) outbreak - an update on the status. Mil Med Res 7(1):11. https://doi.org/10.1186/ s40779-020-00240-0

20. Wu D, Yang XO (2020) TH17 responses in cytokine storm of COVID19: an emerging target of JAK2 inhibitor Fedratinib. J Microbiol Immunol Infect. https://doi.org/10.1016/j.jmii.2020.03.005

21. Hoffmann M, Kleine-Weber H, Schroeder S, Krüger N, Herrler T, Erichsen S, Schiergens TS, Herrler G, Wu NH, Nitsche A, Müller MA, Drosten C, Pöhlmann S (2020) SARS-CoV-2 cell entry depends on ACE2 and TMPRSS2 and is blocked by a clinically proven protease inhibitor. Cell. https://doi.org/10.1016/j.cell.2020.02.052

22. Zhao Y, Zhao Z, Wang Y, Zhou Y, Ma Y, Zuo W (2020) Singlecell RNA expression profiling of ACE2, the putative receptor of Wuhan 2019-nCov. Biorxiv 2020(1):26.919985. https://doi.org/10. 1101/2020.01.26.919985

23. Zou Z, Yan Y, Shu Y, Gao R, Sun Y, Li X, Ju X, Liang Z, Liu Q, Zhao Y, Guo F, Bai T, Han Z, Zhu J, Zhou H, Huang F, Li C, Lu H, Li N, Li D, Jin N, Penninger JM, Jiang C (2014) Angiotensinconverting enzyme 2 protects from lethal avian influenza A H5N1 infections. Nat Commun 5:3594. https://doi.org/10.1038/ ncomms 4594 
24. Huang C, Wang Y, Li X, Ren L, Zhao J, Hu Y, Zhang L, Fan G, Xu J, Gu X, Cheng Z, Yu T, Xia J, Wei Y, Wu W, Xie X, Yin W, Li H, Liu M, Xiao Y, Gao H, Guo L, Xie J, Wang G, Jiang R, Gao Z, Jin Q, Wang J, Cao B (2020) Clinical features of patients infected with 2019 novel coronavirus in Wuhan, China. Lancet 395(10223):497506. https://doi.org/10.1016/S0140-6736(20)30183-5

25. Diao B, Wang C, Tan Y et al (2020) Reduction and functional exhaustion of $\mathrm{T}$ cells in patientswith coronavirus disease 2019 (COVID-19). MedRxiv 2020.02.18.20024364

26. Favalli EG, Ingegnoli F, De Lucia O, Cincinelli G, Cimaz R, Caporali R (2020) COVID-19 infection and rheumatoid arthritis: faraway, so close! Autoimmun Rev 19:102523. https://doi.org/10. 1016/j.autrev.2020.102523

27. Doran MF, Crowson CS, Pond GR, O'Fallon WM, Gabriel SE (2002) Frequency of infection in patients with rheumatoid arthritis compared with controls: a population based study. Arthritis Rheum 46:2287-2293

28. Listing J, Gerhold K, Zink A (2012) The risk of infections associated with rheumatoid arthritis, with its comorbidity and treatment. Rheumatology (Oxford) 52:53-61

29. Turesson C (2016) Comorbidity in rheumatoid arthritis. Swiss Med Wkly 146:1486

30. Smitten AL, Choi HK, Hochberg MC, Suissa S, Simon TA, Testa MA, Chan KA (2008) The risk of hospitalized infection in patients with rheumatoid arthritis. J Rheumatol 35:387-393

31. Monti S, Balduzzi S, Delvino P, Bellis E, Quadrelli VS, Montecucco C (2020) Clinical course of COVID-19 in a series of patients with chronic arthritis treated with immunosuppressive targeted therapies. Ann Rheum Dis. https://doi.org/10.1136/ annrheumdis-2020-217424

32. Yan Y, Zou Z, Sun Y, Li X, Xu KF, Wei Y, Jin N, Jiang C (2013) Anti-malaria drug chloroquine is highly effective in treating avian influenza A H5N1 virus infection in an animal model. Cell Res 23(2):300-302. https://doi.org/10.1038/cr.2012.165

33. Delogu I, de Lamballerie X (2011) Chikungunya disease and chloroquine treatment. J Med Virol 83(6):1058-1059. https://doi.org/10. 1002/jmv.22019

34. Li C, Zhu X, Ji X, Quanquin N, Deng YQ, Tian M, Aliyari R, Zuo X, Yuan L, Afridi SK, Li XF, Jung JU, Nielsen-Saines K, Qin FXF, Qin CF, Xu Z, Cheng G (2017) Chloroquine, a FDA-approved drug, prevents Zika virus infection and its associated congenital microcephaly in mice. EBioMedicine 24:189-194. https://oi.org/ 10.1016/j.ebiom.2017.09.034

35. Dowall SD, Bosworth A, Watson R, Bewley K, Taylor I, Rayner E, Hunter L, Pearson G, Easterbrook L, Pitman J, Hewson R, Carroll MW (2015) Chloroquine inhibited Ebola virus replication in vitro but failed to protect against infection and disease in the in vivo guinea pig model. J Gen Virol 96(12):3484-3492. https://doi.org/ 10.1099/jgv.0.000309

36. Vincent MJ, Bergeron E, Benjannet $\mathrm{S}$ et al (2005) Chloroquine is a potent inhibitor of SARS coronavirus infection and spread. Virol J 2:69

37. Cortegiani A, Ingoglia G, Ippolito M, Giarratano A, Einav S (2020) A systematic review on the efficacy and safety of chloroquine for the treatment of COVID-19. J Crit Care. https://doi.org/10.1016/j. jcrc.2020.03.005

38. Touret F, de Lamballerie $X$ (2020) Of chloroquine and COVID-19. Antivir Res 177:104762. https://doi.org/10.1016/j.antiviral.2020. 104762

39. Gao J, Tian Z, Yang X (2020) Breakthrough: Chloroquine phosphate has shown apparent efficacy in treatment of COVID-19 associated pneumonia in clinical studies. Biosci Trends 14(1):72-73. https://doi.org/10.5582/bst.2020.01047
40. Multicenter collaboration group of Department of Science and Technology of Guangdong Province and Health Commission of Guangdong Province for chloroquine in the treatment of novel coronavirus pneumonia. [Expert consensus on chloroquine phosphate for the treatment of novel coronavirus pneumonia] (2020). Zhonghua Jie He He Hu Xi Za Zhi 43(0):E019. doi: https://doi. org/10.3760/cma.j.issn.1001-0939.2020.0019

41. Yao X, Ye F, Zhang M et al (2020) In vitro antiviral activity and projection of optimized dosing design of hydroxychloroquine for the treatment of severe acute respiratory syndrome coronavirus 2 (SARSCoV-2). Clin Infect Dis. https://doi.org/10.1093/cid/ciaa237

42. Liu J, Cao R, Xu M, Wang X, Zhang H, Hu H, Li Y, Hu Z, Zhong W, Wang M (2020) Hydroxychloroquine, a less toxic derivative of chloroquine, is effective in inhibiting SARS-CoV-2 infection in vitro. Cell Discov 6:16. https://doi.org/10.1038/s41421-0200156-0 eCollection 2020

43. Zhou D, Dai SM, Tong Q (2020) COVID-19: a recommendation to examine the effect of hydroxychloroquine in preventing infection and progression. J Antimicrob Chemother. https://doi.org/10.1093/jac/ dkaa114

44. Gautret P, Lagier JC, Parola P et al (2020) Hydroxychloroquine and azithromycin as a treatment of COVID-19: results of an open-label non-randomized clinical trial. Int J Antimicrob Agents:105949. https://doi.org/10.1016/j.ijantimicag.2020.105949

45. Ouédraogo DD, Tiendrébéogo-Zabsonré W J, Nikiema R et al (2015) Ophthalmologic assessment of patients on hydroxichloroquine followed for systemic disease. [communication] 6th congress of the Ivorian Rheumatology Society (SOCIRh) 2015.Grand-Bassam. Ivory Coast

46. Wang D, Hu B, Hu C, Zhu F, Liu X, Zhang J, Wang B, Xiang H, Cheng Z, Xiong Y, Zhao Y, Li Y, Wang X, Peng Z (2020) Clinical characteristics of 138 hospitalized patients with 2019 novel coronavirus-infected pneumonia in Wuhan, China. JAMA 323: 1061. https://doi.org/10.1001/jama.2020.1585

47. Russell CD, Millar JE, Baillie JK (2020) Clinical evidence does not support corticosteroid treatment for 2019-nCoV lung injury. Lancet 395(10223):473-475. https://doi.org/10.1016/S0140-6736(20)30317-2

48. Cao J, Tu WJ, Cheng W, Yu L, Liu YK, Hu X, Liu Q (2020) Clinical features and short-term outcomes of 102 patients with Corona virus disease 2019 in Wuhan, China. Clin Infect Dis. https://doi.org/10.1093/cid/ciaa243

49. Liu K, Fang YY, Deng Y, Liu W, Wang MF, Ma JP, Xiao W, Wang YN, Zhong MH, Li CH, Li GC, Liu HG (2020) Clinical characteristics of novel coronavirus cases in tertiary hospitals in Hubei Province. Chin Med J 133:1025-1031. https://doi.org/10. 1097/CM9.0000000000000744

50. Zheng C, Wang J, Guo H et al (2020) Anhui Medical team members of National aid to prevent and treat novel coronavirus pneumonia in Wuhan. Risk-adapted treatment strategy for COVID-19 patients. Int J Infect Dis. https://doi.org/10.1016/j.ijid.2020.03.047

51. Luo P, Liu Y, Qiu L, Liu X, Liu D, Li J (2020) Tocilizumab treatment in COVID-19: a single center experience. J Med Virol. https://doi.org/10.1002/jmv.25801

52. Deftereos SG, Siasos G, Giannopoulos G, Vrachatis DA, Angelidis C, Giotaki SG, Gargalianos P, Giamarellou H, Gogos C, Daikos G, Lazanas M, Lagiou P, Saroglou G, Sipsas N, Tsiodras S, Chatzigeorgiou D, Moussas N, Kotanidou A, Koulouris N, Oikonomou E, Kaoukis A, Kossyvakis C, Raisakis K, Fountoulaki K, Comis M, Tsiachris D, Sarri E, Theodorakis A, Martinez-Dolz L, Sanz-Sánchez J, Reimers B, Stefanini GG, Cleman M, Filippou D, Olympios CD, Pyrgakis VN, Goudevenos J, Hahalis G, Kolettis TM, Iliodromitis E, Tousoulis D, Stefanadis C (2020) The GReek study in 
the effects of colchicine in COvid-19 complications prevention (GRECCO-19 study): rationale and study design. Hellenic J Cardiol. https://doi.org/10.1016/j.hjc.2020.03.002

53. Wang W, Ye L, Ye L, Li B, Gao B, Zeng Y, Kong L, Fang X, Zheng H, Wu Z, She Y (2007) Up-regulation of IL-6 and TNF- alpha induced by SARS-coronavirus spike protein in murine macrophages via NF-kappaB pathway. Virus Res 128(1-2):1-8

Publisher's note Springer Nature remains neutral with regard to jurisdictional claims in published maps and institutional affiliations. 